\title{
IDEOLOGIAS DE GÊNERO E IDEOLOGIAS DE LÍNGUA(GEM) EM PÁGINAS FEMINISTAS DO FACEBOOK
}

\author{
Fabiana Poças BIONDO*
}

- RESUMO: O trabalho tematiza a questão das relações entre ideologias de gênero e ideologias de língua(gem), de modo a problematizar a hipótese de convergências entre hegemonias linguísticas e a ordem hegemônica de gênero, fixada pela tradição etnocêntrica ocidental. A partir de exemplos de duas comunidades ativistas feministas da rede social Facebook, investigadas desde 2013 em um estudo etnográfico virtual, o trabalho focaliza a função metapragmática exercida por comentários de participantes dessas comunidades. Orienta-se pela compreensão da linguagem como ação social (BAUMAN; BRIGGS, 1990), pelos conceitos de "ideologia de linguagem" (WOOLARD, 1998), de "conflito discursivo" (BRIGGS, 1996) e de "ataque metapragmático" (JACQUEMET, 1994) e pela apreensão dos processos de construção de identidades em suas relações com as disputas de poder e controle na interação e no mundo social (SIGNORINI, 1998; MOITA LOPES, 2010). Nesses espaços-tempos, as hegemonias de gênero/sexualidade e as hegemonias linguísticas aparecem interligadas, atendendo aos propósitos de (des)credibilização de argumentos, (não) preservação da face e (re)orientação das interações. Isso ocorre sobretudo nas tentativas de normatização do uso da língua(gem), que invocam um modelo cultural escolarizado e estabelecem relação entre esse modelo e a capacidade dos sujeitos de compreensão das questões em discussão, sobre gênero e sexualidade.

- PALAVRAS-CHAVE: Ideologias de gênero. Ideologias de linguagem. Ataque metapragmático. Conflito discursivo. Facebook.

\section{Introdução}

Este trabalho apresenta parte de um estudo etnográfico virtual realizado desde janeiro de 2013 em páginas da rede social Facebook caracterizadas pela militância a favor das causas feministas e anti-homo/trans/lesbofóbicas. Inicialmente, a observação dessas páginas, como "lurker", ${ }^{1}$ deu-se com o objetivo de analisar os significados sobre gênero e sexualidade (co)construídos pelos participantes e melhor compreender

\footnotetext{
Universidade Federal de Mato Grosso do Sul (UFMS), Faculdade de Artes, Letras e Comunicação, Campo Grande MS - Brasil. fabibiondo@gmail.com. ORCID: 0000-0002-0443-4987.

1 Uma espécie de "espreitador cultural" ( a cultural lurker), um leitor que não realiza postagens - cf. sentido dado ao termo pela Etnografia Virtual de Hine (2000, p.24).
} 
a dinâmica da (des)construção de identidades em práticas de uso da linguagem contemporânea. ${ }^{2}$ No entanto, o acompanhamento diário dos posts e das interações nos levou também à observação de que alguns comentários de participantes nos debates revelavam função metapragmática, ou seja, "função tanto de descrever e avaliar quanto de condicionar e orientar os usos da língua na interação oral ou escrita" (SIGNORINI, 2008, p.117). Mais especificamente, recontextualizavam regulamentações grafocêntricas institucionalizadas sobre a língua, ao mesmo tempo em que revelavam normas socioculturalmente estabelecidas sobre gênero e (re)orientavam a interação nesses espaços.

A observação dessa dinâmica permitiu-nos configurar uma nova questão que julgamos de interesse ao campo aplicado dos estudos da linguagem e a qual focalizamos neste trabalho: a função metapragmática exercida por alguns comentários de participantes e a hipótese de relacionamento entre hegemonia linguística e outras ordens hegemônicas estabelecidas, como as de gênero e sexualidade fixadas pela tradição etnocêntrica ocidental. E, para lidar com essa questão, nossa imersão nesses espaços passou a ser guiada pelas seguintes questões de investigação: Que ideologias de língua(gem) estão presentes nas páginas? Que ideologias de gênero ${ }^{3}$ estão presentes nas páginas? De que forma uma e outra (ideologias de gênero e de língua/gem) se relacionam nessas páginas?

Diante dos múltiplos dispositivos linguísticos e socioculturais mobilizados pelos participantes em suas performances de uso da língua, que exibem também variadas conotações ideológicas, trazemos para discussão, neste trabalho, os "conflitos" (BRIGGS, 1996) e os “ataques metapragmáticos" (JACQUEMET, 1994) relacionados a dois valores culturais interligados e extremamente presentes nas páginas estudadas: 1) os conceitos de masculinidade/feminilidade e 2) os ideais de língua padrão e de correção linguística.

Inicialmente, apresentamos a metodologia da pesquisa, uma breve contextualização das páginas feministas do Facebook estudadas e, na sequência, passamos às bases teóricas; finalmente, trazemos para discussão duas sequências geradas por duas publicações feitas pelos moderadores nas páginas "Moça, você é machista" e "Diários de uma feminista". Como pretendemos mostrar, os embates não apenas instanciam um modelo cultural normativo e escolarizado de uso da língua, como também revelam o estabelecimento de relações entre esse modelo, as ideologias ligadas ao gênero/à sexualidade e a capacidade dos sujeitos de compreender e participar das questões em discussão.

Resultados dessas análises foram publicados em Biondo (2015) e em Biondo e Signorini (2015).

Usamos o sintagma "ideologias de gênero", neste estudo, para nos referir a quaisquer questões ideológicas e relações de poder que permeiam a hegemonia do masculino e da heterossexualidade em nossa sociedade. Usamos a expressão, ainda, e deliberadamente, para nos contrapor à sua apropriação pejorativa no Brasil, atualmente, por meio da qual se desqualifica o próprio campo de estudos de gênero. 


\section{Metodologia da pesquisa}

A pesquisa foi realizada em oito páginas do Facebook que se caracterizam como ativistas das causas de gênero. Seis dessas páginas foram acompanhadas desde janeiro de 2013 e outras duas páginas foram adicionadas à investigação em junho de 2016. Em comum, as oito páginas se denominam como "comunidade" e apresentam objetivo de militância/ativismo contra o preconceito, a desigualdade e todas as formas de violência de algum modo ligadas às causas das minorias focalizadas: em geral mulheres, homossexuais e transexuais; mas também negros, crianças e outros tidos como marginalizados. Todas essas páginas são públicas e podem ser curtidas e seguidas por qualquer usuário do Facebook. A partir da Etnografia Virtual (HINE, 2000), acompanhamos diariamente as discussões nas páginas, apenas observando (lurker), sem escrever postagens.

A Etnografia Virtual, conforme Hine (2000), tem como foco a imersão do pesquisador em espaços online de interação, bem como as relações entre esses espaços e os offline. Tem suas bases na etnografia tradicional, mas, ao deslocar seus interesses para o ambiente online, exige que esta seja reconfigurada, sobretudo no que diz respeito às percepções do espaço, do lugar, do tempo e da identidade. Tais percepções, na Etnografia Virtual, precisam ser guiadas pela situação específica a ser investigada, bem como pelo contexto sociocultural - em sintonia com o modo como a própria pesquisa é compreendida nessa perspectiva.

De modo simples, pode-se dizer que todos esses construtos (espaço, lugar, tempo e identidade) só existem, em tal perspectiva, como um "campo de relações" estruturado em função dos aspectos culturais e sociais de uma dada situação específica, nunca anteriores à prática, nunca como conceitos preestabelecidos e fixados (HINE, 2000). Além disso, tempo e espaço estão em situação de determinação, constituindo-se como "espaço-tempo" - sempre definido pela ação social em curso, amparado por uma riqueza de recursos materiais e discursivos e imerso nas relações de poder (LEANDER; MCKIM, 2010). Na investigação de espaços-tempos online, como os das páginas do Facebook analisadas neste estudo, Hine (2000) acredita que é necessário dar grande importância à linguagem e à interação estabelecida, no lugar da imersão prolongada do pesquisador em campos físicos que constitui a etnografia tradicional.

\section{As páginas feministas investigadas}

Para este trabalho, selecionamos duas das oito páginas que compõem o nosso corpus: "Moça, você é machista" e "Diários de uma feminista". A escolha por essas duas páginas justifica-se por elas apresentarem o maior número de curtidas e de seguidores à época das análises aqui apresentadas (Tabela 1). A primeira foi criada em abril de 2012 e é definida apenas como uma "página criada por teóricos queer feministas"; já a segunda foi criada em outubro de 2014 e é apresentada como uma "página feminista 
interseccional-marxista" que publica, "além de textos e posts didáticos, conteúdos de humor feminista: contradiscurso e ironia". ${ }^{4}$ No quadro abaixo, apresentamos os dados dessas comunidades referentes ao recorte temporal definido para a coleta de registros deste trabalho (junho a setembro de 2017):

Quadro 1 - Dados sobre as duas páginas feministas investigadas no estudo

\begin{tabular}{|c|c|c|c|c|}
\hline & \multicolumn{2}{|c|}{ Moça, você é machista } & \multicolumn{2}{|c|}{ Diários de uma feminista } \\
\hline & \multicolumn{2}{|c|}{860 mil curtidas; 851 mil seguidores } & \multicolumn{2}{|c|}{741 mil curtidas; 740 mil seguidores } \\
\hline 2017 & Posts & Ten & Posts & \\
\hline Junho & 20 & \multirow{5}{*}{$\begin{array}{l}\text { pedofilia, doutrinação religiosa, } \\
\text { estado laico, aborto, estupro, } \\
\text { política atual, homofobia, } \\
\text { transfobia, estereótipos e } \\
\text { violência contra a mulher, } \\
\text { machismo, queer, racismo, etc. }\end{array}$} & 202 & \multirow{5}{*}{$\begin{array}{l}\text { pedofilia, inversão de } \\
\text { estereótipos, machismo, padrões } \\
\text { de beleza femininos, homofobia, } \\
\text { política atual, racismo, } \\
\text { misandria, etc. (a grande maioria } \\
\text { com deboche e ironia) }\end{array}$} \\
\hline 10 & 15 & & 0 & \\
\hline w w & 24 & & 53 & \\
\hline Setembro & 12 & & 197 & \\
\hline TOTAL & 71 & & 452 & \\
\hline
\end{tabular}

Fonte: Elaboração própria.

Os posts em que focamos neste texto são aqueles que apresentaram o maior número de reações (Curtir, Amei, Haha, Uau, Triste, Grr), de comentários e de compartilhamentos, nos meses selecionados, dentre aqueles que apresentavam comentários de função metapragmática relacionados aos valores culturais de masculinidade/feminilidade e de correção linguística. ${ }^{5}$ A escolha desses posts foi motivada, ainda, pelo fato de que eles exibem parte representativa dos embates de natureza metapragmática que configuram ideologias de gênero e de linguagem nesses espaços-tempos da globalização.

\section{Ideologias de língua(gem) e metapragmáticas da língua em uso}

Conforme lembrou Woolard (1998), a forma como definimos o que é língua ou linguagem define também nossa relação com o universo sociocultural, pois revela o modo como compreendemos a organização dos seres humanos como indivíduos, em suas instituições e interrelações. A despeito das diversas formas de compreensão do conceito de language ideology em diversas tradições de pesquisa, a autora opta por defini-lo como "representações, explícitas ou implícitas, que interpretam o cruzamento entre a linguagem e os seres humanos em um mundo social" (WOOLARD, 1998, p.4).

\footnotetext{
4 Informações disponíveis nas páginas estudadas. Dados atualizados em 12/10/2017, às $17 \mathrm{~h} 45$.

5 Ambas as páginas apresentavam alto fluxo interacional nos meses investigados. Em alguns posts da comunidade "Moça, você é machista", as reações chegavam 10 mil, os comentários a mais de 800 e os compartilhamentos a 30 mil. Já na comunidade "Diários de uma feminista", alguns posts atingiram mais de 5 mil reações, mais de 500 comentários e de mil compartilhamentos.
} 
Language ideology é apreendido por Woolard (1998), portanto, em sua relação com um conjunto de crenças e noções compartilhadas sobre a estrutura e racionalização de uma língua, em suas articulações com os aspectos socioculturais. Nesse sentido, a autora lembra que o termo pode ser tomado como "ideologia linguística", "ideologia de língua" ou "ideologia de linguagem", formas que ela compreende como intercambiáveis, embora algumas tradições de uso estabeleçam separação entre elas. No caso deste trabalho, interessa-nos particularmente uma tradição de estudos, advindos da antropologia linguística, que se concentra na ideia de ideologia linguística, focalizando a análise de estruturas linguísticas em seus aspectos sociais e discursivos. Em geral, tais estudos tomam por base o conceito de metapragmática, que se apresenta tanto por meio de comentários explícitos quanto de comentários implícitos na reflexão e no uso da linguagem (SILVERSTEIN, 1979).

Em trabalho mais recente, publicado no Brasil, Moita Lopes (2013, p. 20) chamou a atenção para a natureza discursiva da língua, discutindo o conceito de ideologia linguística a partir de sua relação com os modelos socioculturais da linguagem em uso pelos falantes e escritores do "português no nosso caso" e do português dos estudiosos do campo da linguagem. Para o autor, "as ideologias linguísticas são múltiplas e advém de perspectivas políticas, culturais e econômicas específicas" (MOITA LOPES, 2013, p. 21), estruturando-se a partir de práticas sócio-historicamente situadas e relacionadas inclusive às perspectivas epistemológicas de seu tempo. Em assim sendo, defende o autor, as ideologias linguísticas podem responder a interesses de grupos sociais específicos e só podem ser apreendidas localmente. Desse modo, "qualificar um modo de falar de língua é uma decisão política, um dado antropológico, um produto ideológico por excelência" (BAGNO, 2013, p. 323).

Para Signorini (2008, p.119), as ideologias linguísticas são sistemas culturais de ideias e de crenças que fazem parte das nossas práticas sociais e que os falantes articulam para avaliar o uso linguístico, do ponto de vista moral e político, de tal forma que elas acabam por delimitar "a inclusão/exclusão dos falantes em redes, práticas e instituições". Elas se relacionam, portanto, aos discursos de função metapragmática, ou seja, aqueles que, de forma direta ou indireta, explicita ou implícita, acabam por "descrever, avaliar, condicionar e orientar" os usos da língua em interações sociais (SIGNORINI, 2008, p.117). Para a autora,

as metapragmáticas da língua em uso num dado espaço/tempo são sempre heterogêneas e dinâmicas em diferentes graus porque resultam da sinergia de um aglomerado de fatores inter-relacionados, que vão desde a propriedade reflexiva da própria língua, associada às capacidades metalinguística e metacomunicativa dos falantes, até as dimensão sóciohistórico-cultural e político-ideológica das práticas de uso oral e escrito da língua e dos discursos sobre como são/como devem ser os usos linguísticos na interação social. (SIGNORINI, 2008, p.119). 
São essas metapragmáticas, segundo a autora, que orientam as disputas políticoideológicas que compõem as avaliações dos falantes sobre a língua em uso nas interações. Sejam tais disputas explicitadas ou não, elas respondem por descrever e regulamentar o que tem ou não valor, é ou não adequado, pode ou não ser dito/escrito por determinadas pessoas ou grupos, em função das "circunstâncias contextuais" e de redes sociais de poder e de autoridade (SIGNORINI, 2008).

As disputas de natureza político-ideológica que ocorrem em interações especificamente localizadas, das quais trata a autora, evidenciam o caráter de ação social (BAUMAN; BRIGGS, 1990) da língua em uso. Sendo esta de natureza espaçotemporal situada, política e ideológica, sua natureza reflexiva torna-se essencial para que se possa agir com a língua e sobre ela, em diversas situações sociointeracionais do nosso dia a dia (SIGNORINI, 2008). No que segue, tratamos particularmente de disputas discursivas e de ações reflexivas de uso da língua denominadas "conflitos" e "ataques metapragmáticos".

\section{"Conflitos" e "ataques metapragmáticos"}

Conforme lembrou Briggs (1996), o processo de diferenciar um "Outro" a partir de um "Eu" é crucial não apenas para a construção de identidades, mas também para a organização de comunidades. Nas páginas ativistas do Facebook investigadas, as disputas discursivas exibem claramente esse processo, em um contexto de confronto por meio do qual os participantes (re)negociam, a todo tempo, o seu universo social, (re)definindo e (des)construindo suas identidades sexuadas e generificadas no contato com a alteridade (BIONDO; SIGNORINI, 2015).

Tais páginas chamam a atenção, portanto, para o que Briggs (1996) nomeou "conflitos" discursivos. Para o autor, é o processo conflituoso, o impasse, que importa para a exibição das formações sociais: "é no contexto do confronto - quando as pessoas negociam seu universo social e entram no discurso sobre isso - que o caráter desse sistema é revelado" (BRIGGS, 1996, p.5). A negociação do universo social via embates/ conflitos ideológicos que se dão na interação social é discutida por Briggs (1996) também em relação ao caráter de ação social impresso no uso da linguagem. Nesse sentido, o autor fala da necessidade de que se compreenda, em definitivo, que o uso da linguagem não apenas reflete, mas também constitui relações de poder e de dominação. Isso pode ser identificado observando-se as estratégias de manipulação utilizadas por interactantes no conflito, de forma consciente ou não, para atingir interesses que the são próprios, por um lado, e para estabelecer normas e regras, por outro.

Um caso ilustrativo dessas estratégias de dominação sociointeracionais é apresentado por Jacquemet (1994), ao lidar com o contexto de tribunal. Como mostra o autor, os participantes de um embate no tribunal geralmente fazem grandes malabarismos no uso da linguagem, visando estrategicamente proteger sua própria face ou derrubar um oponente. O fazem, ainda, imbuídos de valores comunitários locais, códigos de honra e demais 
recursos que são mobilizados com o objetivo de embutir credibilidade ao que se diz e dominar a interação. Nesses casos, os envolvidos recorrem a recursos sociointeracionais e a valores culturais, usando conceitos sociais como o de masculinidade, por exemplo, para galgar respeito e gerenciar as impressões desejadas. Em geral, o fazem a partir do que Jacquemet (1994) nomeou "ataques metapragmáticos", em performances de linguagem organizadas em função de determinadas ideologias. Ao produzir seus efeitos na consciência do falante individual e na percepção das relações interpessoais, alguns usos linguísticos se revelam como uma verdadeira "exibição ideológica", funcionando, em alguns contextos, como um "ataque metapragmático".

Mas, para que um comentário metalinguístico possa ser considerado como um ataque metapragmático, é preciso avaliar seu efeito perlocutivo na situação específica em que ocorre. Apenas a intenção do falante não é suficiente; é preciso que o destinatário ou o público reconheça, na conversa (de forma direta) ou por meio de posturas afetivas (forma indireta), as mudanças comunicativas em jogo (como o silêncio, a retirada/ ruptura interacional, ou reações dramáticas, etc.) para que se tenha, de fato, um evento metapragmático (JACQUEMET, 1994).

De todo modo, são os recursos explícitos de metalinguagem, sejam eles reconhecidos como ataques metapragmáticos ou não, que moldam e estruturam o contexto situacional a partir do qual interpretamos a realidade social. Trata-se de ação que envolve a definição de limites comunicativos responsáveis por determinar 'quem está 'dentro' e quem está 'fora' (identidade social), quem ‘tem' e quem não ‘tem' (variações sociais e de classe), quem 'pode' e quem não 'pode' (estrutura de poder)", como bem lembrou Jacquemet (1994, p.303).

\section{Ideologias de gênero e performatividade}

Em um contexto sociocultural caracterizado pela transitoriedade e incompletude das identidades, facilmente identificável no acentuado contato com a alteridade que configura os espaços-tempos da globalização, as comunidades feministas do Facebook trazidas para discussão neste trabalho são representativas da multiplicidade de discursos, culturas e sociabilidades que entram em confronto e (re)definem identidades em tais espaços-tempos (BIONDO, 2015).

Para Moita Lopes (2010), sobretudo por conta da internet, que amplia as possibilidades de contato com o Outro, está se tornando a cada dia mais difícil reduzir as identidades a significados únicos, sendo necessário compreendê-las a partir de uma complexidade de posicionamentos, desestabilizando categorias essencialistas e caminhando para um movimento de "pós-identidades". É nessa direção que caminha a epistemologia feminista pós-moderna, ao promover a desestabilização das categorias de mulher, gênero e patriarcado e ao problematizar as noções de poder que as constituem (SARDENBERG, 2002; NARVAZ; KOLLER, 2006, entre outros). 
Enquanto vertente do feminismo pós-moderno, a teoria da performatividade do gênero (BUTLER, 2003[1990]; LOURO, 2008; MOITA LOPES, 2007) permite um olhar para a identidade em sua relação com a linguagem, pois se desenvolveu fundamentada na teoria dos atos de fala de Austin (1962) e em seus desdobramentos nas teorias da performance, que ganharam destaque nos anos 70/80. Compreender o uso da linguagem como ação social implica, entre outras coisas, na valorização do significado indicial, em detrimento do referencial ou simbólico, em um olhar atento às relações entre contexto micro e macro de processos comunicativos, aos usos dinâmicos e situados da língua. Abre-se espaço, portanto, à investigação de significados outros que não os já fixados pela tradição etnocêntrica ocidental, permitindo o questionamento da ordem hegemônica sobre língua(gem) e sociedade (BAUMAN; BRIGGS, 1990).

É sob essa perspectiva que atua a teoria da performatividade de gênero, questionando a "norma de inteligibilidade do gênero" (BUTLER, 2003[1990], p. 39) fixada pela cultura moderna, que busca estabelecer uma relação objetiva entre sexo, gênero e comportamento social: se alguém nasce "mulher", deve ter comportamento e traços tidos como "femininos" e se relacionar com um "homem". Essa norma é subvertida por Butler (2003[1990]) quando ela afirma que as identidades de gênero não existem de forma independente da ação social, mas só podem ser construídas performativamente, por meios dessas ações e das estruturas de poder que as sustentam: "não há identidade de gênero por trás das expressões de gênero; essa identidade é performativamente constituída, pelas próprias 'expressões' tidas como seus resultados" (BUTLER, 2003[1990], p. 48).

Assim, mesmo que em uma determinada cultura algumas identidades de gênero não sejam consideradas "lógicas", por conta da norma estabelecida, é a existência dessa mesma norma que permite que a subvertamos, questionando suas regulações e apresentando outras vias para pensar identidades de gênero. Dessa forma, tais identidades só podem ser tomadas no interior das expressões ideológicas em que estão imersas - sejam essas expressões binaristas e compulsórias (macho/fêmea; homem/mulher; heterossexual/homossexual); sejam elas transcendentes, movidas por instabilidades, por ressignificações e pelo questionamento da formação de poder que sustenta a hierarquia dos gêneros.

De todo modo, as expressões e construções de gênero costumam ser guiadas por performances de linguagem, segundo Butler (2003[1990]). Para a autora, ao enunciarmos "é uma menina", quando do nascimento de um bebê, estamos agindo nomeando essa criança e iniciando um processo de "ser menina" no mundo social. Abre-se, então, um conjunto de pressupostos ideológicos sobre a mulher que passam a regular sua existência, pautados em normas e em regras pré-definidas para este lado do binário. Já ao ensaiar outras possibilidades (performances) para o ser mulher, ampliase o campo para a subversão e a ressignificação dessas normas. Sob tal perspectiva, o gênero é sempre uma construção, sujeito a instabilidades, e se dá ao longo de toda uma vida, continuamente, de modo infindável. Essa construção, por sua vez, ocorre por 
meio de diversas experiências de aprendizagens e de práticas sociais, num processo que é "minucioso, sutil, sempre inacabado" (LOURO, 2008, p.18).

\section{Embates metapragmáticos nas páginas feministas}

Os participantes das interações nas páginas do Facebook investigadas, em geral fazem malabarismos com dois tipos de estratégias: as que servem para afirmar e defender os propósitos e ideais ativistas dessas páginas e as que se direcionam a questionar e a desestabilizar esses ideais. Tais estratégias se organizam por meio de diversos recursos metadiscursivos, que vão desde a retomada e avaliação de enunciados anteriores feitos por um mesmo participante até observações e críticas a enunciados escritos por outros participantes. Em última instância, elas respondem ainda pela dinâmica interacional desses espaços, que, segundo observaram Biondo e Signorini (2015), caracterizam-se pela disputa e pela acomodação de opiniões, crenças e visões de mundo, nas muitas tentativas de (des)estabilização de noções essencialistas sobre o que é culturalmente permitido ao ser homem e ao ser mulher em nossa sociedade.

Nesses embates, observamos que os participantes se utilizam de códigos socioculturais sobre as questões de identidade tematizadas nas páginas, de códigos estabelecidos nas próprias páginas e de estratégias comunicativas relacionadas ao ideal de "credibilidade", para alcançar três objetivos interrelacionados: dar confiabilidade a argumentos apresentados; desautorizar argumentos; dominar a interação. E, para atingir esses objetivos, lançam mão de variados dispositivos socioculturais, em performances linguísticas organizadas em função das conotações ideológicas impressas nas páginas. Para analisar tais dispositivos e performances na enunciação estabelecida nas páginas feministas, pautamo-nos, ainda, no conceito de indexicalidade, o qual permite indicar a relação entre tais performances, seus aspectos discursivos e os aspectos históricos, sociais e culturais que mobilizam e aos quais dão visibilidade (BLOMMAERT, 2006).

A indexicalização é um construto teórico-analítico por meio do qual podem se analisar os recursos semióticos como índices, guiando o processo de significação simultaneamente por meio de escalas micro e macro contextuais. Assim, conforme Silverstein (2003), as marcas/índices linguísticos passíveis de serem apreendidos localmente na enunciação sinalizam as ações dos participantes nela envolvidos, e estão sempre pautadas por convenções e projeções de natureza textual, semiótica e social. A interpretação de uma determinada situação discursiva é, portanto, sempre contextualizada, e sinaliza (indexica) aspectos culturais locais e compartilhados. Dessa forma, o que chamamos de "fato indexical" relaciona-se com as normas de uso e as regras sociais indicadas por determinados signos, pois todo e qualquer signo indexical é capaz de criar e de pressupor contextos específicos, apontando para tais contextos e para as regularizações que os caracterizam (SILVERSTEIN, 2003).

Dois dos dispositivos socioculturais apreensíveis via indexicalidade mais utilizados pelos participantes das comunidades feministas, e que nos interessam particularmente 
aqui, são: 1) os ligados aos conceitos sociais de masculinidade/feminilidade; 2) os relacionados ao ideal de língua padrão e de correção linguística. Ambos são valores culturais bastante recorrentes nas estratégias comunicativas desses espaços, servindo tanto ao objetivo de dar confiabilidade quanto de desabonar opiniões e argumentos. É o que demonstra o exemplo abaixo, transcrito da página "Moça, você é machista":

Figura 1 - Publicação feita pelo moderador da página "Moça, você é machista".

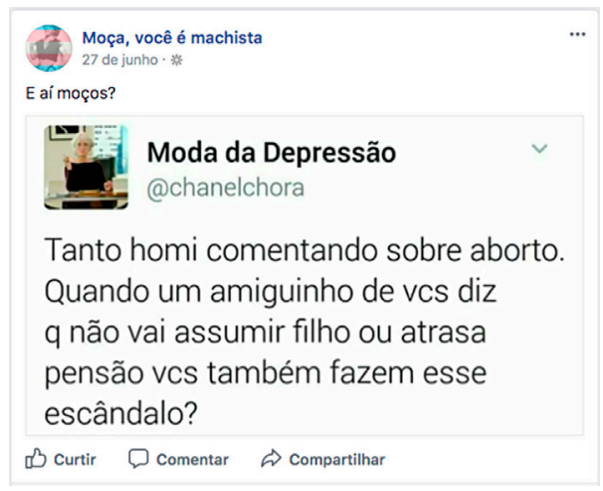

Fonte: https://www.facebook.com/MocaVoceEMachista/. Acesso em: 14 out. 2017.

\section{Exemplo 1 - comentários ${ }^{6}$}

Tadeu: Nao tenho nenhum amigo q tem filhos, nenhum caiu no golpe da barriga

Talita: Adivinha pq nenhum dos seus amigos têm filhos [:

Caren: Queridinho, Punheta não engravida ninguém. Todo mundo sabe que seus abiguinhos bolsominions são virgens e provavelmente nunca deixarão de ser. E não adianta descarregar a frustração de vocês nas mulheres, eu sei que é mais fácil culpar as feministas, a internet, a sociedade mas não adianta tapar o sol com a peneira: vocês são ridículos e mesmo que conseguissem uma mulher para transar não saberiam o que fazer com ela nos 10 segundos de empolgação. Agora vai fazer o dever de casa antes que mamy te coloque de castigo. Paspalho.

Denise: Migo, é porque comer o bumbunzinho dos parça não engravida ninguém.

Tadeu: Oi? Kkkkkkkkkm quando a sexualidade entrou em pauta? Que legal, só falar algo pra uma fêmea mimizenta q não concorda, q os comentarios sobre sexualidade começa kkkkkkk como se gay nao tivesse amigos heteros... melhorem femeas frustradas

Carla: Jesus....a humanidade está realmente perdida... golpe da barriga, fêmeas frustada. Deus, me diga por que não criou limite para ignorância e intolerância humana?

6 A partir dos critérios de exclusão de comentários semelhantes e dos que fugiam à temática do post, transcrevemos apenas alguns dos 62 comentários feitos a esse post, de 27 de junho a 8 de outubro de 2017. A partir desses critérios e por questão de espaço, também omitimos partes de alguns comentários, marcando a omissão por: [...]. Todos os nomes dos participantes foram substituídos e os comentários transcritos da mesma forma como aparecem nos originais. 
Helena: Para de falar merda fio. Golpe da barriga? Coitados de vcs, tão inocentes! Nem sabem como se faz um filho, como se evita...

Tadeu: Quem nao sabe evitar filho é burro... coitada das mulheres, nunca engravidaram pra segurar macho ne?! So na minha sala conheço umas 5 ... macho burro tem q se fuder msm

Deise: BURN!

Ana: Uma pessoa de minoria (gay) destilando preconceito. Menino, você precisa aprender a viver! Reseta esse ódio de mulher pq tá bem deplorável.

Tadeu: Deplorável quando uma "minoria" acha q todoa tem q swr igual, colocando sempre essa "minoria" como santa imaculada... dai quando tu fala q mulher nao é santa, que existe mulher tão sem vergonha quanto homem, é odio por mulher... santa paciência

Ana: Não imaculei nada. Só penso que quem sente na pele o preconceito instaurado socialmente pelo que é simples e fisiologicamente poderia ter mais empatia. Você não falou que mulher não é santa, você taxou as mulheres de serem tão dependentes de macho a ponto de dar 'golpe' da barriga. Te contar, Você é muito jovem ainda, dá tempo de ter empatia e também de entender que as mulheres não concentram a sua vida em dar golpe em omi ou fazer deles o centro de suas vidas. Beijas

Tadeu: Ana vc sabe que existe casos de mulher engravidar pra segurar macho, e não são poucos... como eu disse na minha sala são 5 ... dois dos casos sao bem.proximos a mim, mas o que ves gostam de fazer é colocar a mulher como santa e o homem o malvadao... igual os próprios gays, gays santos e heteros malvadao, gay provoca ate levar uma coça, pra depois gritar homofobia... exiate sim motivação diferente pra violência em gays e mulheres... mas eles participar dessa "minoria" não faz eles santos. Empatia eu tenho com a dona maria q apanhou do marido, da melissa que está na prostituição por falta de oportunidade, pq uma mulher trans na empresa, estraga a empresa, para o próprio feminismo que se fala tanto de empatia, ridicularizar falando q é um homem maquiado e vai chamar ela por nome social sim...

Vânia: Golpe da barriga é ótimo kakakaa ta bom criança. Você já provou que é um dos homens citados. Toma aqui seu biscoitinho

Ana: Minha Deusa, vai aprender a escrever suas opiniões e depois você volta. Nem entendi nada do que você disse acima. Como disse a moça, pega teu biscoitinho de macho, um leite quente e vai nanar criança.

Tadeu: Mimimi vai aprender a escrever kkkk alem de td é sinica kkkkkkk

Ana: Cínica : 10

Tadeu: Como vc preferir $:-2$,

Anita: Tô vendo o golpe da barriga onde o pai do bebê mora com os pais, não tem ensino médio, não tem emprego e não tem onde cair morto... puta golpe da barriga esse!!! Kkkkkk

Tadeu: O golpe da barriga é so algo financeiro? Kkkkkkkkk

Ivo: Vcs são todos muito mal educados viu, que discussão horrível de ler... 
Tadeu: Ivo a minha educação depende da sua educação...

No exemplo, a postagem compartilhada pelo moderador em junho de 2017 inicia uma discussão sobre a temática do aborto, dirigindo-se em forma de deboche aos homens que estavam se manifestando contrários na página. $\mathrm{O}$ deboche pode ser inferido pela escolha da construção lexical não reconhecida HOMI (variante OMI), muito comumente utilizada nas comunidades para se referir aos homens considerados machistas e imaturos. A imaturidade é um valor social da ordem de indexicalidade bastante mobilizado, aliás, na discussão que se segue, conforme se pode ver nos comentários transcritos acima, em que as participantes Caren, Denise, Ana e Vânia se valem de recursos linguísticos como o diminutivo ("abiquinhos", "bumbunzinho", "biscoitinho") e de elementos que remetem ao campo semântico da infância ("leite quente", "amiguinhos", "nanar", "criança", "mammy" e "bolsominions") para descredibilizar os argumentos de Tadeu, tido como um exemplo de "omi" ("Você já provou que é um dos homens citados") a que se dirigem muitos dos comentários da comunidade - os que se opõem às ideias nela defendidas, em geral por mulheres, e que são considerados machistas.

É Tadeu, aliás, quem garante a instauração do conflito discursivo, logo no primeiro comentário ao post, ao se posicionar contrariamente aos ideias da comunidade e mobilizar uma expressão bastante usada para ofender as mulheres, acusadas de engravidar para "dar um golpe" - no caso, "segurar" um homem ("Nao tenho nenhum amigo q tem filhos, nenhum caiu no golpe da barriga " " "',"). E, em outros momentos da discussão, ao utilizar de outras expressões que significam nessa direção, indexicando valores machistas que remetem à cultura patriarcal ("segurar macho"; "mulher não é santa"; "santa imaculada"; "macho burro") ou às acusações em geral feitas a mulheres feministas ("fêmea mimizenta"; "femeas frustradas").

Em forma de reação aos comentários de Tadeu, Talita, Caren, Denise, Helena, Carla, Deise, Ana e Vânia recorrem a recursos linguísticos e interacionais diversos, na tentativa de descredibilizar o "omi” que provocou o conflito, quando desestabilizou o argumento do post. Além do uso do diminutivo, chama a atenção o recurso aos valores da ordem de indexicalidade de ignorância e de intolerância humana, utilizado por Carla (“Deus, me diga por que não criou limite para ignorância e intolerância humana?’); da inversão de responsabilidades tradicionalmente atribuídas à mulher, na cultura do patriarcado, como se vê no próprio post feito pela moderadora, que levanta a questão da corresponsabilidade do homem pelos seus filhos ("Quando um amiguinho de ves diz q não vai assumir filho ou atrasa pensão vcs também fazem esse escândalo?’); da referência ao conceito de misoginia, feita por Ana ("Reseta esse ódio de mulher pq tá bem deplorável").

O recurso ao diminutivo e ao próprio valor de imaturidade, por sua vez, relacionase a um outro valor indexical, extremamente mobilizado nas comunidades feministas estudadas: o de masculinidade. No exemplo transcrito da comunidade Você é machista, toda a discussão é enquadrada em forma de "ataque" à masculinidade de Tadeu e de seus "amiguinhos", não apenas pelo uso do diminutivo, mas também pelo questionamento 
de suas "performances" sexuais, por Caren ("seus abiquinhos bolsominions são virgens e provavelmente nunca deixarão de ser; mesmo que conseguissem uma mulher para transar não saberiam o que fazer com ela nos 10 segundos de empolgação") e, sobretudo, pelo uso do gênero marcado, por Ana, para se dirigir a Tadeu ("Minha Deusa"). No caso deste último recurso, que nos interessa mais particularmente aqui, ao violar claramente uma regra da língua portuguesa que é, em si mesma, reveladora de normatizações linguísticas e sociais de gênero, o comentário de Ana funciona como um "ataque metapragmático", aludindo à masculinidade de Tadeu e funcionando como afronta às religiões conservadoras, que costumam representar Deus como figura masculina. Convencionalmente, o gênero gramatical não marcado é um índice linguístico morfológico normalmente utilizado para referir-se a sujeitos do sexo masculino, enquanto o gênero marcado, por desinência, convencionou-se como referência a sujeitos do sexo feminino. Ao violar essa regra, chama-se a atenção para o valor indexicalizado de feminilidade tradicionalmente relacionado pejorativamente aos homossexuais e para o valor cristão da figura masculina.

O ataque metapragmático é estabelecido ainda, por Ana, no mesmo comentário em que se dirige no feminino a Tadeu, quando ela faz uso explicitamente de um outro valor de indexicalidade para questionar e descredibilizar os argumentos de seu interlocutor: o de normalização/correção linguística. Nesse caso, chama a atenção o fato de Ana relacionar a capacidade de Tadeu de escrever coerentemente suas opiniões e o direito que ele tem de participar da discussão/da comunidade ("vai aprender a escrever suas opiniões e depois você volta"), bem como a avaliação pessoal que ela faz da forma como Tadeu escreve, com base em sua própria capacidade de compreensão ("Nem entendi nada do que você disse acima"). Nesse momento, fica claro que ideologias linguísticas de correção e purismo da língua, tradicionalmente escolarizadas, relacionam-se às ideologias de gênero nas comunidades investigadas, de modo a estabelecer que aqueles que não dominam a ordem hegemônica de correção linguística também não dominariam, automaticamente, questões ideológicas e conhecimentos sobre gênero e sexualidade.

Os ataques metapragmáticos são confirmados ainda na conversa, pelo próprio destinatário, quando Tadeu retoma o comentário de Ana, debochando e acusando-a de cinismo ("Mimimi vai aprender a escrever kkkk além de td é sinica kkkkkk"). Logo na sequência, porém, Ana volta a corrigir a escrita de Tadeu, dessa vez recorrendo a uma regulamentação grafocêntrica/ortográfica para mostrar que a palavra usada por Tadeu para xingá-la deve ser escrita com a letra $\mathrm{C}$ e com acento gráfico na vogal i ("Cínica ' " O faz, ainda, de forma debochada, como se infere pelo uso do emotion com a piscadinha.

A partir desse momento, a discussão se enfraquece e são feitos apenas quatro ou cinco comentários curtos e sem grandes argumentações ou ataques, até que ela se encerre, como se pode ver nas transcrições dos comentários. Assim como em vários outros exemplos de interações nas comunidades investigadas, esse é um desdobramento bastante comum: os ataques metapragmáticos desestabilizam a discussão e, embora sejam feitas tentativas de mantê-la em terreno firme, pela utilização de discursos de autoridade, exemplos, 
elementos espaciais e temporais da ordem do real e "confiável", entre outros, em geral eles levam a um enquadre da conversa no nível da passionalidade, com xingamentos, deboches, pouca argumentação e retirada interacional de interlocutores. Isso é ainda mais evidente, nas páginas feministas, quando os ataques remetem explicitamente a valores da ordem de indexicalidade correção e normalização linguística. Esses, em geral, respondem também por uma tentativa de definir quem tem e quem não tem o "direito" de participar das interações nesses espaços-tempos da globalização.

Curioso notar, nesses casos, que geralmente o uso da ideologia linguística de correção e normalização é mobilizado indexicalmente justamente pelas feministas e defensoras dos valores das comunidades. Do mesmo modo, são elas que, normalmente, estabelecem os ataques metapragmáticos - embora quase sempre em defesa, a partir da instauração de um conflito discursivo pelos que se enquadram contrariamente aos ideais feministas. Contrariando a própria dinâmica da pluralidade que orienta e constitui as lutas pela subversão das noções hegemônicas de gênero em espaços ativistas, a língua é tomada, pelas feministas, de modo totalitário e homogêneo, remetendo a uma ideologia linguística pautada em valores normativos e escolarizados. Parece-nos, portanto, que a defesa da pluralidade e a resistência à ordem hegemônica estabelecida, nesses espaços, ainda não chegou na língua.

Figura 2 - Publicação feita pelo moderador da página "Diários de uma feminista".

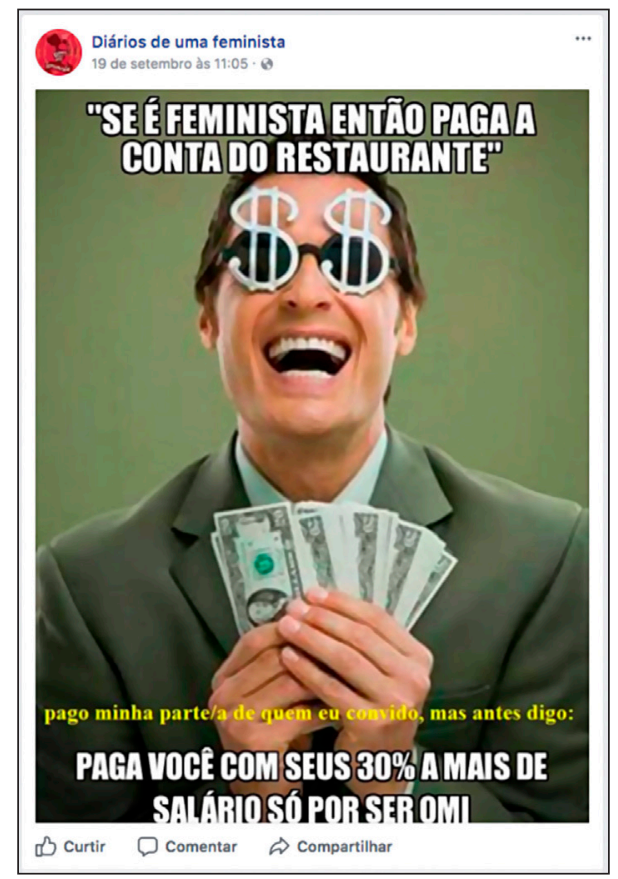

Fonte: https://www.facebook.com/diariosdeumafeminista/. Acesso em: 14 out. 2017. 


\section{Exemplo 2 - comentários ${ }^{7}$}

Valmir: 30\%?????? Fonte: carta capital, quebrando o tabu, blablabla...

Beatriz: Quem é a senhorita pra desmerecer o trabalho dos funcionários da carta capital?

Valmir: É “senhor”, Beatriz. Eu sei q ves são confusos com a própria sexualidade e como devem tratar os gêneros, com suas doenças mentais de esquerda, mas pela foto percebe-se que sou homem. O "trabalho" da Carta Capital é lamber e polir o saco do Lula e promover toda agenda da esquerda no Brasil. Não estou desmerecendo, eles fazem o trabalho muito bem, criando desinformação, mentindo, caluniando pessoas, espalhando cultura de esgoto.

Beatriz: E a senhora pode provar essa acusação sobre eles?

Valmir: Beatriz, não enquanto vc não aprender a ter algum respeito. Vcs exigem respeito, mas na hora de se dirigir a uma pessoa ficam com essa porrinha... se falar comigo direito, falo com vc direito. Se continuar a faltar com respeito, vá à merda.

Beatriz: Enquanto ve for escrota eu vou debochar da sua cara 100 Além do seu argumento vir apenas do fato de não concordarem com a sua visão política, vc não é absolutamente ngm com intelecto e conhecimento o suficiente pra falar assim de alguém que estudou pra fazer o que faz. Se manque, imunda.

Valmir: Beatriz, ok, eu vou dar a sua resposta, mesmo ve sendo uma escrota do caralho e faltando com respeito, só pq é divertido fazer ves passarem vergonha. Todo mundo sabe que a porra da Carta Capital é esquerdista. Quer falar de intelecto? https://oglobo.globo.com/.../ odebrecht-emprestou-verba...

Valmir: Folha tb noticiou, seu animal. http:/www1.folha.uol.com.br/.../1875168-lula-emantega...

Beatriz: Entao pq a carta capital é de esquerda eles tem menos créditos que a palavra de um professor de piano? ATA LKKKKKKKKKKKKKKKKKKKKK

Beatriz: Como provar que a carta capital nao tem credibilidade: Pega uma notícia dizendo que em 2007 um político ajudou financeiramente.

Valmir: Foi no meu perfil pessoal fuçar minha vida???? huahuahuahua vc é mais vulgar e escrota do que esperava! Eu não sou o assunto, retardada! Eu não tenho site, não promovo porra nenhuma! Foda-se se sou professor de piano, esse não é o argumento. Vc reclamou que queria que eu provasse a acusação, eu dou a prova e vc muda o argumento pra quem tem mais crédito!!!! Caralho, é de fuder a lógica heim!!!!! Quem recebe propina NÃO TEM CRÉDITO, sua imoral cretina, não interessa minha vida particular, eu não perguntei a sua, quero q vc se foda, se for professora ou prostituta, caguei. Queria a prova, tá aí.

Beatriz: Muito prostituta sim $\bullet$ Na vdd ve nn provou absolutamente nd. E o que ser vulgar tem a ver com abrir uma ft de perfil e ler comentários?

Usando os mesmos critérios de seleção do exemplo 1, transcrevemos apenas parte dos 32 comentários feitos, de 19 a 20 de setembro, no post. 
Valmir: Beatriz “um político"?? Vc é analfabeta ou só cretina mesmo? Eu disse q a revista puxa saco do Lula e tem delação mostrando que Lula deu dinheiro. Não é "um político" qualquer, vc pode fingir demência, mas não é um político qualquer. Bom, já dei atenção demais pra vc. Estava sendo babaca, e mesmo assim respondi, vc conseguiu ser mais babaca e mudou o argumento por pura diarréia mental.

Beatriz: O dia que vc conseguir provar realmente que os funcionários da carta capital dão notícias falsas ve vai poder TENTAR debater. E pq ficou tão putinha? Tá infeliz com a sua vizinha de professor?

Beatriz: Ue gente, Lula não é político não? Que estranho

Valmir: Tem tudo a ver. O debate só é debate no campo das ideias. Qd vc começa a fuçar a vida das pessoas pra ter argumento, vc é um animal baixo, vulgar, e burro que não tem capacidade de argumentar sobre o assunto, acha q tem q vencer pela depredação pessoal. Enfim. A prova tá á. Não gostou, enfia o dedo e se rasga. Não tenho mais o q responder pra vc. Adios.

Beatriz: "Diarréia mental" BERRO

Como uma pessoa tão tapada consegue ensinar algo a alguém? KKKKKKKKKKKKKKKL

Beatriz: Ta ofendido pq professor não tem a capacidade de se meter em assunto de jornalista?

Beatriz: O mais engraçado é vc falar que eu sou vulgar por ir olhar seu perfil mas veio numa Page feminista só pra causar briga.

Beatriz: Professor tao bom que não tem nd melhor pra fazer numa manhã de quarta feira além de brigar no facebook (?)

No exemplo 2, o embate é estabelecido apenas entre dois participantes da comunidade: Valmir e Beatriz. De modo diferente ao que ocorre no exemplo 1, nesse caso o "ataque metapragmático" ocorre já no início da interação, quando Beatriz reage ao comentário de Valmir, que instaura o conflito discursivo questionando a credibilidade da informação apresentada pelo moderador da comunidade (" $30 \%$ ?????? Fonte: carta capital, quebrando o tabu, blablabla..."). A reação de Beatriz ocorre via ataque metapragmático quando ela mobiliza o valor da ordem de indexicalidade masculinidade/feminilidade, quebrando a regra gramatical que estabelece o uso do gênero não marcado para o masculino e utilizando deliberadamente o gênero marcado (normativamente estabelecido para o feminino) para se dirigir a Valmir ("Quem é a senhorita"), de forma a atacar sua masculinidade e descredibilizar seus argumentos, a exemplo do que costuma ocorrer nesses espaços-tempos.

$\mathrm{O}$ ataque é confirmado imediatamente na sequência interacional, pela reação de Valmir, que não apenas corrige explicitamente Beatriz (“É “senhor”, Beatriz”), mas também se vale do fato de ela ter subvertido a regra linguístico-gramatical de gênero para relacionar essa subversão à da norma identitária de gênero/sexualidade socialmente estabelecida ("Eu sei q vcs são confusos com a própria sexualidade e como devem tratar os gêneros"). Nesse momento, ideologias de gênero e ideologias linguísticas se 
relacionam explicitamente, uma vez que, para Valmir, do mesmo modo que Beatriz subverte a norma linguística estabelecida para o gênero gramatical, ao usar a desinência de feminino para se referir a um sujeito tido como do sexo masculino, ela também subverte a norma de gênero e sexualidade estabelecida pela tradição - a que seria bem estabelecida e não permitiria "confusões" na forma de "tratar os gêneros". O participante busca reafirmar sua masculinidade e sua posição contrária a essas subversões ("mas pela foto percebe-se que sou homem"). Beatriz, por sua vez, mantém-se em seu posicionamento e continua a dirigir-se a Valmir com o uso do gênero marcado, como se verifica em outros momentos da interação ("senhora", "escrota", "imunda", "putinha").

Valmir associa tais subversões, ainda, a uma postura política esquerdista ("com suas doenças mentais de esquerda") - algo também bastante comum nas comunidades estudadas, em que se associam as posições feministas a uma ideologia político partidária de esquerda. Esta ideologia, aliás, parece incomodar Valmir ainda mais que os ataques metapragmáticos. Tanto o é que quando a participante feminista instaura outro ataque metapragmático, relacionado aos padrões linguísticos e de conhecimento intelectualmente "aceitos" pela ordem social escolarizada (padrões aos quais, inclusive, as próprias feministas costumam se alinhar, conforme vimos mostrando), ele não revida o ataque a partir do questionamento desses padrões, mas sim por ideologia político partidária. É o que ocorre quando Beatriz diz que ele não "estudou” e, portanto, não teria o direito de se posicionar, de opinar sobre os assuntos em discussão ("vc não é absolutamente ngm com intelecto e conhecimento o suficiente pra falar assim de alguém que estudou pra fazer o que faz") e isso passa batido por Valmir, que volta a enquadrar a discussão no campo das ideologias partidárias ("Todo mundo sabe que a porra da Carta Capital é esquerdista"). Parece-nos, portanto, que também para os contrários aos ideais defendidos na comunidade há maior invisibilidade quando a questão é o ataque aos ideais de conhecimento/escolaridade tradicionalmente estabelecidos.

Chama a atenção ainda, nesse exemplo, o fato de que o ataque metapragmático, instaurado desde o início do embate, como forma de reação ao conflito discursivo iniciado por Valmir, desestabiliza e enfraquece todo o restante da interação, que passa a se estruturar basicamente por meio de xingamentos, tanto de Valmir ("vá à merda"; "escrota do caralho"; "retardada"; "imoral", "cretina" etc.), quanto de Beatriz ("escrota"; "imunda"; "putinha" etc.). Ao ter sua masculinidade atacada, Valmir sente o ataque, explicita-o e se desestabiliza interacionalmente, agindo de forma passional ao mesmo tempo em que busca restabelecer o poder interacional, recorrendo a fontes que considera mais confiáveis que a apresentada pelo moderador ("https://oglobo.globo.com/.../ odebrecht-emprestou-verba..."; "Folha tb noticiou, seu animal http://www1.folha.uol. com.br/.../1875168-lula-e-mantega...”), de forma a mobilizar discursos de autoridade e a se alinhar a uma ideologia político partidária contrária à que ele relaciona com os "doentes mentais" ("com suas doenças mentais de esquerda") - ou seja, os defensores da pluralidade de gênero.

Nesse momento, uma vez mais, vemos as relações entre questões ideológicas ligadas ao gênero e outras ordens hegemônicas estabelecidas em nossa sociedade. Isso porque, 
ao dizer que as feministas/esquerdistas são confusas com "a própria sexualidade" e com a forma de "tratar os gêneros", com suas "doenças mentais", o participante mobiliza valores da ordem de indexicalidade da homossexualidade ou qualquer subversão à norma tradicional do gênero como doença. Como sabemos, trata-se de valor bastante difundido, atualmente, pelas forças reacionárias que se opõem fortemente aos estudiosos do gênero e a todos aqueles que o tomam em perspectiva flexível e performativa.

O recurso aos discursos de autoridade e às ideologias político partidárias, porém, não é suficiente para que Valmir restabeleça o poder interacional, e a discussão se mantém enfraquecida em termos de argumentos até que se encerre, com a retirada interacional do participante Valmir (“Adios"). Como ocorre no exemplo 1 e em vários outros exemplos das comunidades, portanto, os ataques metapragmáticos costumam fortalecer os conflitos discursivos, enfraquecer a utilização de argumentos, aumentar a propensão ao uso de discursos de autoridade e, principalmente, enquadrar as interações no campo da passionalidade, por meio do uso de muitos vocábulos de conotação pejorativa e de retiradas interacionais de interlocutores.

Tais movimentos, parece-nos, revelam muitas das relações, estabelecidas nas comunidades ativistas investigadas, entre ideologias linguísticas e ideologias identitárias de gênero e de sexualidade, sobretudo no que se refere às: aproximações entre subversão de gênero e subversão da língua; aproximações entre ignorância linguística (e intelectual) e ignorância sobre questões de gênero e, finalmente, contradições entre o resistir às hegemonias de gênero e o reforçar de estruturas hegemônicas sobre a língua.

\section{Considerações finais}

Neste trabalho, trouxemos para discussão dois exemplos dos muitos embates estabelecidos nas comunidades ativistas de gênero do Facebook que vimos investigando desde 2013, em uma pesquisa de natureza etnográfica virtual. Com nova questão de investigação, que começou a se desenhar no final de 2015, focalizamos a função metapragmática que alguns comentários dos participantes dessas comunidades assumem, ao revelar ideologias de língua(gem) pautadas na descrição, na avaliação de usos linguísticos, bem como direcionadas a condicionar e a orientar esses usos, com base no que definiu Signorini (2008).

Conforme se pôde ver pelos exemplos analisados, são muitos os malabarismos de linguagem feitos pelos participantes, tanto com o objetivo de defender os ideais que são conclamados pelas páginas ativistas, quanto com o objetivo de derrubá-los. Isso, por meio da utilização de variados recursos sociolinguísticos e metadiscursivos, sobretudo pela retomada de enunciados anteriores, no sentido de questioná-los, reforçá-los ou reconduzir a interação em função de determinados interesses.

Os casos analisados são emblemáticos dessa dinâmica, que se instaura em grande parte nos embates e conflitos identificados nas páginas feministas. Uma dinâmica que se estrutura a partir de códigos e condutas socioculturamente estabelecidos, 
em performances linguísticas pautadas especialmente em dispositivos ideológicos relacionados aos ideais de masculinidade/feminilidade e de adequação/inadequação de usos linguísticos, em nossa sociedade.

Atravessando-se mutuamente, nesses espaços-tempos que dão muita visibilidade às noções de poder imbricadas ao estabelecimento de identidades e classes sociais e de estruturas de dominação, as hegemonias de gênero/sexualidade e as hegemonias linguísticas identificadas nas comunidades respondem aos objetivos sociointeracionais de (des)credibilizar argumentos, preservar ou não a face dos interlocutores e (re)orientar as interações. Diante desses objetivos, os comentários tanto instanciam modelos culturais tradicionalmente escolarizados sobre o uso da língua quanto estabelecem relação entre esse modelo e a capacidade dos sujeitos de compreensão das questões em discussão, sobre gênero e sexualidade. São esses modelos que parecem terminar por definir, nas páginas, quem está ou não autorizado a participar das discussões, e de que forma - a depender de critérios identitários e linguísticos baseados nas estruturas de poder de nossa sociedade.

BIONDO, F. Gender ideologies and language ideologies on facebook feminist pages. Alfa, São Paulo, v. 63, n.2, p.295-315, 2019.

- ABSTRACT: The present study deals with issues of relations between gender ideologies and language ideologies, with a view to discussing the hypothesis of convergence of linguistic hegemonies and hegemonic order of gender, secured by Western ethnocentric tradition. It has been developed on the basis of examples extracted from two Facebook feminist activist communities. The latter have been subjected to investigation since 2013 by a virtual ethnographic study. This research focuses on the metapragmatic function exerted by comments made by participants of those communities. It is guided by understanding language as social action (BAUMAN and BRIGGS, 1990), the concepts of "language ideology" (WOOLARD, 1998), discursive conflict (BRIGGS, 1996), and "metapragmatic attack" (JACQUEMET, 1994), as well as by comprehending processes of identity construction in relation to power dispute and control within interaction and the social world (SIGNORINI, 1998; MOITA LOPES, 2010). Gender/sexuality hegemonies as well as linguistic hegemonies are co-articulated in space-time, thus fulfilling the purposes of (dis)crediting arguments, achieving (non)keeping of participants'face, and (re)orientation of interactions. This particularly occurs in an attempt to render language use normative, which evokes a school-related cultural model and is capable of establishing relations between such a model and the ability individuals have to understand issues of gender and sexuality under discussion.

- KEYWORDS: Gender ideologies. Language ideologies. Metapragmatic attack. Discursive conflict. Facebook. 


\section{REFERÊNCIAS}

AUSTIN, J. L. How to Do ings with Words. Oxford: Clarendon Press, 1962.

BAGNO, M. Do galego ao brasileiro, passando pelo português: crioulização e ideologias linguísticas. In: MOITA LOPES, L. P. (org.). O português no século XXI: cenário geopolítico e sociolinguístico. São Paulo: Parábola, 2013. p. 319-338.

BAUMANN, R.; BRIGGS, C. Poetics and performances as critical perspectives on language and social life. Annual review of Anthropology, Palo Alto, CA, v.19, n.1, p.59-88, 1990.

BIONDO, F. P. Liberte-se dos rótulos: questões de gênero e sexualidade em práticas de letramento em comunidades ativistas do Facebook. Revista Brasileira de Linguística Aplicada, Belo Horizonte, v.15, n.1, p.209-236, 2015.

BIONDO, F. P.; SIGNORINI, I. (Re)definições e (des)construções identitárias em comunidades ativistas do Facebook: contribuições das epistemologias pós-feminista e queer. DELTA: Documentação e Estudos em Linguística Teórica e Aplicada, São Paulo, v.31 n. esp. 4, p. 169-197, 2015.

BLOMMAERT, J. Social linguistics scales. London: King's College, 2006. (Working Papers Urban Language e Literacies).

BRIGGS, C. Disorderly discourse: narrative, conflict, \& inequality. Oxford: Oxford University Press, 1996.

BUTLER, J. Problemas de gênero: feminismo e subversão da identidade. Rio de Janeiro: Civilização Brasileira, 2003[1990].

HINE, C. Virtual ethnography. London: Sage Publications, 2000.

JACQUEMET, M. T-offenses and metapragmatic attacks: strategies of interactional dominance. Discourse \& society, Stanford, v.5, n.3, p.297-319, 1994.

LEANDER, K. M.; MCKIM, K. K. Tracing the everyday 'sitings' of adolescents on the internet: A strategic adaptation of ethnography across online and offline spaces. Education, Communication \& Information, London, v.3, n.2, p.211-240, 2010.

LOURO, G. L. Gênero e sexualidade: pedagogias contemporâneas. Pro-posições, Campinas, v.19, n.2, p.17-23, 2008.

MOITA LOPES, L. P. Ideologia linguística: como construir discursivamente o português no século XXI. In: MOITA LOPES, L. P. (org.). O português no século XXI: cenário geopolítico e sociolinguístico. São Paulo: Parábola, 2013. p. 18-52. 
MOITA LOPES, L. P. Os novos letramentos digitais como lugares de construção de ativismo político sobre sexualidade e gênero. Trabalhos em Linguística Aplicada, Campinas, v.49, n.2, p.393-417, 2010.

MOITA LOPES, L. P. Se eu fosse mulher...: performances de gênero e sexualidade em Como gostais. In: MOITA LOPES, L. P. (org.) Performances. Rio de Janeiro: Contracapa, 2007. p.79-102.

NARVAZ, M. G.; KOLLER, S. H. Metodologias feministas e estudos de gênero: articulando pesquisa, clínica e política. Psicologia em Estudo, Maringá, v.11, n.3, p.647-654, 2006.

SARDENBERG, C. M. B. Da crítica feminista à ciência a uma ciência feminista. Feminismo, Ciência e Tecnologia, Salvador, v.8, n.1, p.1-35, 2002.

SIGNORINI, I. Metapragmáticas da língua em uso: unidades e níveis de análise. In: SIGNORINI, I. (org.). Situar a lingua[gem]. São Paulo: Parábola, 2008. p.117-148.

SIGNORINI, I. Figuras e modelos contemporâneos da subjetividade. In: SIGNORINI, I. (org.). Língua(gem) e identidade. Campinas: Mercado de Letras, 1998. p.333-380.

SILVERSTEIN, M. Indexical order and dialetics of sociolinguistic life. Language e communication, Oxford, n.23, p. 193-229, 2003.

SILVERSTEIN, M. Language structure and linguistic ideology. In: CLYNE, P. R; HANKS, W. F.; HOFBAUER, C. L. The elements: A parasession on linguistic units and levels. Chicago: Chicago Linguistic Society, 1979. p. 193-247.

WOOLARD, K. A. Language Ideology as a Field of Inquiery. In: WOOLARD, K. A. et al. Language Ideology: Practice and Theory. New York: Oxford University Press, 1998. p. 2-40.

Recebido em 28 de fevereiro de 2018

Aprovado em 11 de agosto de 2018 